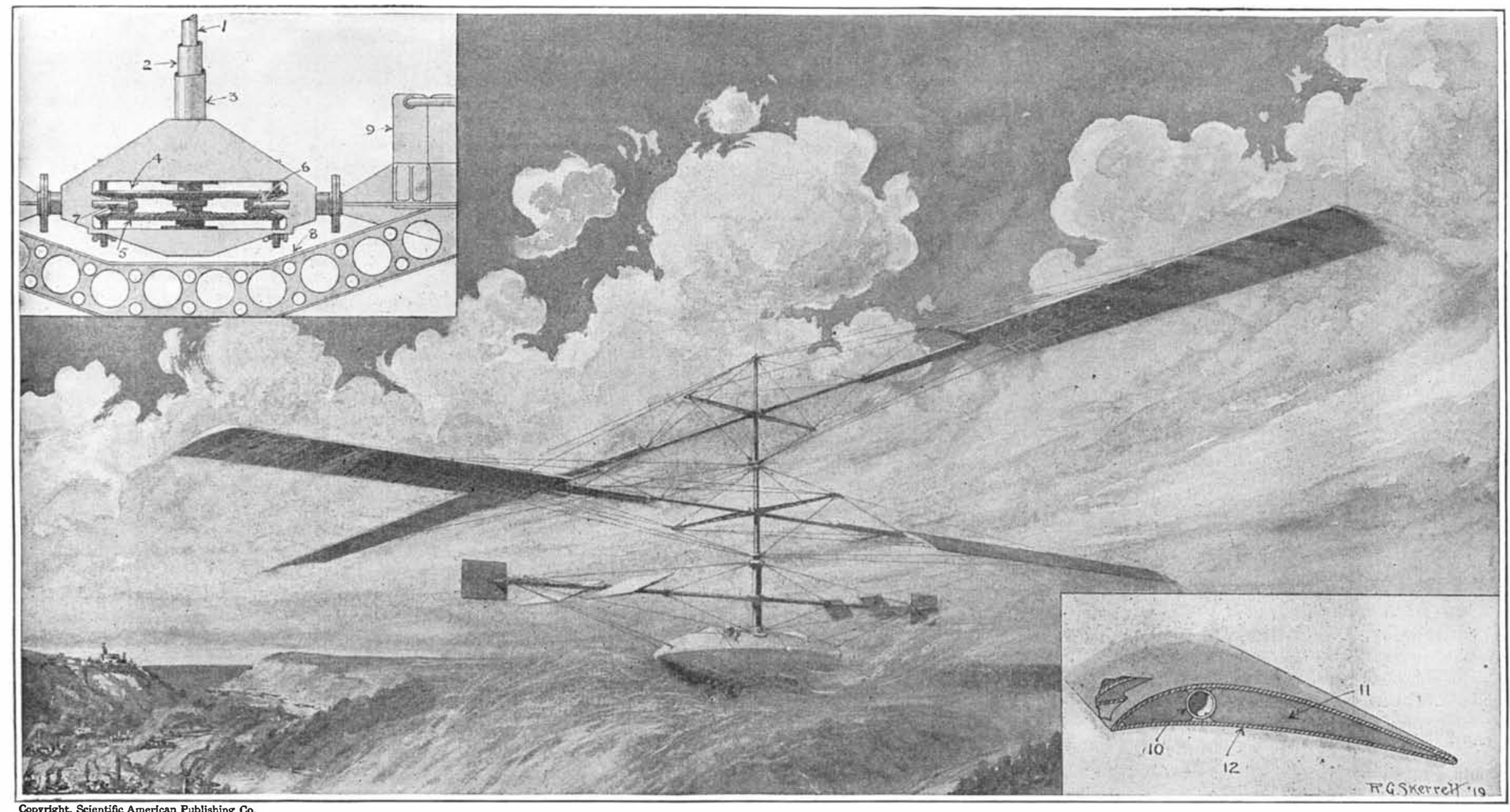

How the helicopter of Professor Francis B. Crocker and Dr. Peter Cooper Hewitt would appear in flight, and some details of the transmission and the revolving wings

\title{
Again the Helicopter?
}

\section{Experiments by Prominent Inventors Who Hope to Realize This Long-Standing Dream By Robert G. Skerrett}

\begin{abstract}
To one familiar with the art of mechanical flight, relatively inefficient intrume airplane propen-that a very large percentage of the power delivered by the good hold upon the air. To make matters worse, this "slip" grows in geometric ratio as the speed of revolution mounts higher and higher. Therefore, to provide the needful measure of sustentation, the flying machine's wings are given more and more surface in order to utilize the buoyant reactions of the atmosphere; for the wings are relatively much better able to play their part in keeping the craft aloft than is the propeller, as it exists in general service.
\end{abstract}

The basic reasons for the screw's handicap are its moderate size, its rotary velocity, and the elastic nature of the medium in which it works. Airplane propellers, according to the catalogs, are built to make anywhere from 1,200 to more than 2,000 revolutions a minute, and they vary in size from 5 feet to about 10 feet in diameter. When going at their designed speeds, these screws send rearward a column of violently disturbed air, and, what is more to the point, they set up pronounced perturbations over a considerable area in the air ahead. Therefore, the propeller moves forward into a medium upon which its grip is discounted by the extent of this agitation; the larger the number of revolutions a minute the greater is this hampering factor.

On the other hand, the airplane's wing surfaces meet the impinging air under far more favorable circumstances, and the reactions thus induced are in the main of a buoyant or lifting nature in effect. Thanks to the revelations of the wind tunnel, aeronautical experts have been able to design wing forms of an extremely efficient character which, for every square foot of surface, provide a remarkable amount of sustention But this solution invokes an increase of wing-speed with every increase of power and capacity; and the size of the airplane increases, the problem grovs apace of effecting a safe landing and of getting off the ground without mishap. The giant plane's very bulk and weight invite hazards, especially if the craft be forced to the ground after dark or be obliged to come to earth where a suitable stretch of cleared and fairly smooth country is not available.

If we were to assert unqualifiedly that a promising alternative for the airplane, and one which presents hope of eventually overcoming the drawbacks enumerated, lay in the helicopter, we should probablyand justly-be greeted with shouts of derision. "What, that old chestnut!" our critics would exclaim. "Why, that has been exploded more times than we can count." Well, so it has; current opinion with regard to the helicopter, the machine that goes straight up by bor-

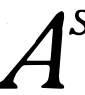
S Mr. Skerrett says in his introductory remarks, it would be a bold spirit who would claim that the helicopter, that much ridiculed scientific freak, is a practicable means of flight. But in the age when humans $f y$ at all, in the age of wireless and the X-ray and the apparent verification of the Einstein theories, it would be an even more rash citizen who would assert with equal positiveness that the helicopter is inherently absurd and incapable of serious development. At any rate, with true modern spirit, two eminent engir.eers have set out to see what they can make of the aerial corkscrew. The article tells us of the line their experiments have taken, and of the degree to which they are inclined to claim success.-THE EDITOR.

the time; but before the tests were concluded it was amply demonstrated that a helicopter had been producd of a unique form which might come to stand in a class distinct from those machines of an allied type which had proved so disappointing. Doctor Hewitt and Professor Crocker accomplished their ends by breaking away from the lines of endeavor previously pursued by engineers and inventors. In particular they appear to have produced propellers of a far more efficient order than any airplane screws now on the market. Indeed, this may rightly be said to have been the key to their attacks upon the problem.

The airplane propeller that develops a lift or thrust of 10 pounds per horse-power on a fast machine is the exception rather than the rule, and a very large number of them do not give more than 6 or 7 pounds per engine horse-power. This would not do, of course, in a helicopter, where lift and sustention must be secured by the thrust of the screws alone. The primary object of the research was to obtain propellers that would give a thrust of not less than 12 to 15 pounds for fast machines and anywhere from 20 to 40 pounds per horsepower for practical weight-carrying helicopters. The propellens finally produced gave a lift of 2,550 pounds for 126.5 horsepower when making but $\mathbf{7 0}$ revolutions a minute! That is, the thrust was at the rate of 20.2 pounds per horse-power.

The machine was deliberately overweighted so that it could not rise-the

ing a hole in the air, is so unflattering that many an aviation expert wolld hesitate to have his name linked with the effort to make it practicable. But sometimes wise men rush in where fools fear to tread. And the bald fact which we have to chronicle is that two no less notable engineers than Peter Cooper Hewitt and Francis Bacon Crocker have produced a helicopter which has developed a lift of 4,000 pounds with motors of 200 horse-power.

The machine was assembled and put through its paces at Ampere, New Jersey, last year. It was called into being as a possible aid in fighting the Teutons, and the cessation of hostilities stopped further trials for problem of landing again being one it was desired for the present to avoid. Had it been free to ascend it must have done so, because the thrust obtained was nearly 300 pounds in. excess of the total weight of the helicopter itself. The measure of the lift was established by carefully calibrated platform scales; and readings of the thrust at different speeds of rotation and varying driving powers were indicated on a largefaced dial. For the time being, airplane engines were replaced by two electric motors each of 100 horsepower. These were used not only to permit experymental speeds from the very lowest and on up gradually to the higher rotary velocities, but likewise to 
enable the investigators to check up by the electric meters the power consumed at any moment.

The propellers employed had diameters of 51 feet; were mounted one above the other upon concentric shafts; and, being respectively right-and-left handed screws, were revolved in opposite directions. They were placed vertically 7 feet apart so that the effectiveness of the lower wheel, working in the wake of the upper one, was as little affected as practicable by the disturbance set up in the air. Operating in this manner, the propellers alone exert a strong stabilizing force.

Because of the great diameter of the screws, it is possible to obtain the needful peripheral speed when they are driven at a relatively low angular velocity, and the blades are able to work upon a large mass of air without setting up the violent perturbations which characterize the reactions provoked by the usual types of airplane propellers. Therefore, it is practicable to use blades that act upon the air much after the manner of airplane wings. As M. Gustave Eiffel has made clear, by his memorable work in his laboratory at Auteuil, the vacuum created at the back of an airplane wing is much the larger factor in the total lift impulse produced. Accordingly, the desire was to take advantage of this phenomenon in designing the blades for the two propellers with which the helicopter was equipped. The blades were made of an aeroform model, 30 inches wide and about 15 feet long, and they were secured to the outer portions of tubular steel arms each $251 / 2$ feet in length. This caused the blades to follow paths where their impact with the air would be most effective.

By attaching the blades to the supporting arms forward of the center of pressure, the arms, instead of pushing the blades through the air, thus draw them onward. This arrangement obviates the risk of "chattering," and, by introducing a measure of elasticity, allows the blades, within some limits to adjust their pitch angle automatically and to accommodate themselves to changing atmospheric stresses. The blades are built up of aluminum partitions placed transversely, and are then sheathed upon their upper and lower surfaces with the same material. This construction provides the desired degree of strength and, incidentally, makes them fireproof. It will be observed that the blades are placed at a distance from the propeller hub, so to speak, and in this way is avoided that mass of material which characterizes the usual airplane screw just where the speed of revolution is too low to produce a commensurate or helpful measure of thrust. Manifestly, these helicopter propellers are remarkably light judged by their effectiveness, and yet are strong enough to meet all service requirements.

Having elected to adapt the aeroform wing to propellers of especially large diameters and low angular

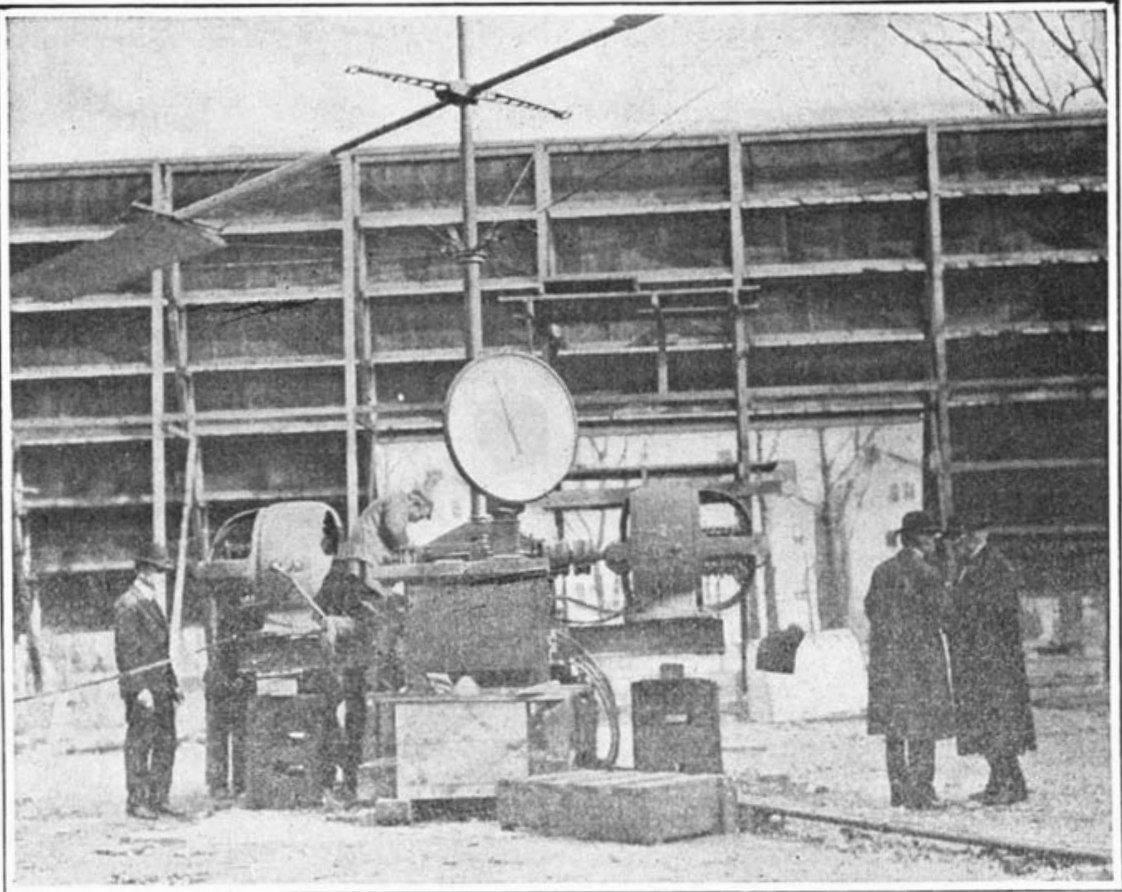

Two electric motors used to drive the helicopter, and the lift indicator
Steam Locomotive and Passengev Coach Combined

THIS is the old story about necessity 1 being the Mother of Invention but the invention, in this case, is decidedly new, and that is why we are telling the story here. The story opens up with two brothers, F. E. and F. O. Stanley, who owned lands and a large hotel near Denver, Colorado, and found that while there was a railroad to their property, the transportation was not adequate and it was certainly anything but attractive and comfortable.

These brothers have for years been identified with the development of the steam automobile; and so it did not take them long to build a larger engine than that used in their pleasure car. This engine they installed in what is known as the "mountain wagon." This wagon carried several passengers and while entirely satisfactory for the purpose intended, it could hardly take the place of the railroad which will always be the accepted method of land travel when distance combined with comfort is the paramount consideration.

However, the "mountain wagon" attracted the attention of one of the offcials of a big trunk line railroad in the West. This official convinced the Stanleys that there are innumerable places where railroad transportation is needed but cannot be made profitable when a train consisting of a locomotive and coaches must be hauled to carry the light traffic. Nor can the roads afford to electrify in order to haul a single-car train. The power houses, overhead or third-rail construction; rail bonds, and so on, represent an investment that is entirely out of reach.

And in this manner the steam unit car shown in the two accompanying illustrations, was developed. A car was built and put in service on a road in New England. The first boiler installed was a fire tube boiler. This was changed to $\mathbf{a}$ water tube boiler of very rugged construction. This car, which operated for something over two years, proved so successful and showed such promise that it attracted the attention of a large firm in Boston, which later took over the unit car for manufacture and marketing.

The car is propelled by a modified twin cylinder engine mounted on and forming part of the forward truck, power being transmitted direct to the axle by a spur gear, the engine and driving gear running in an oil bath in an oil-tight case. The power developed (approximately 60 horse-power) is about one-third of that developed by the average locomotive which hauls a dozen or more coaches, and when periods of emergency exist, such as starting on heavy grades, bucking snowdrifts, or making up time, View of the central shaft and one of the revolving wings

interposed, and it was equally plain that the gear should have the dual characteristics of positiveness of contact and flexibility to meet the changing stresses (Continued on page 594)

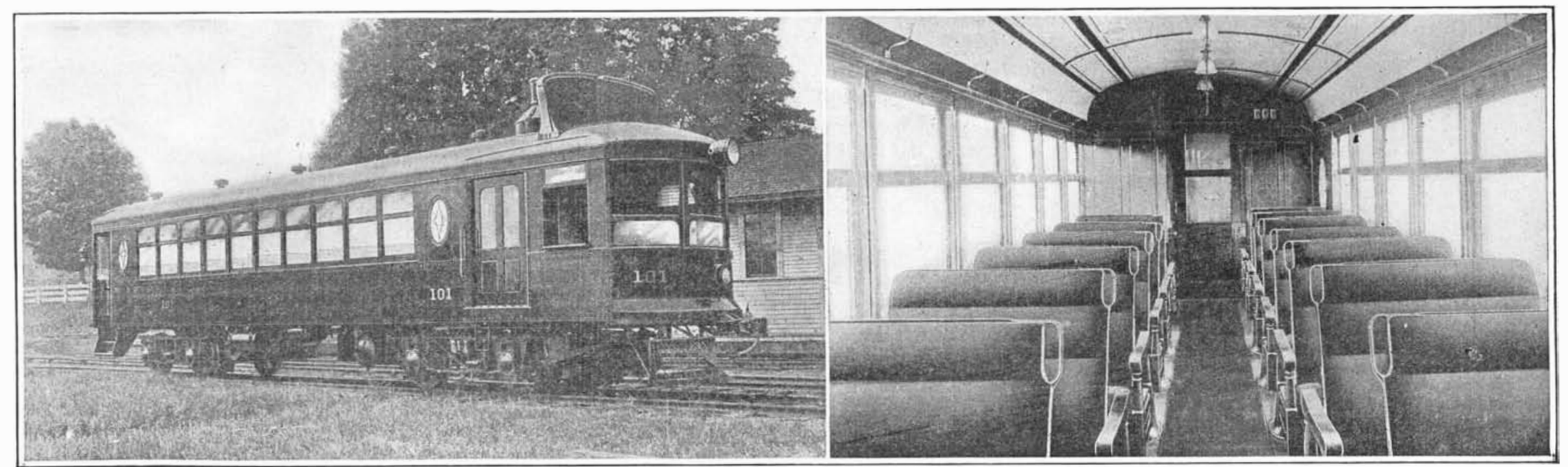

Steam unit car which has been designed for traffic on branch lines, and a view down the passenger compartment 


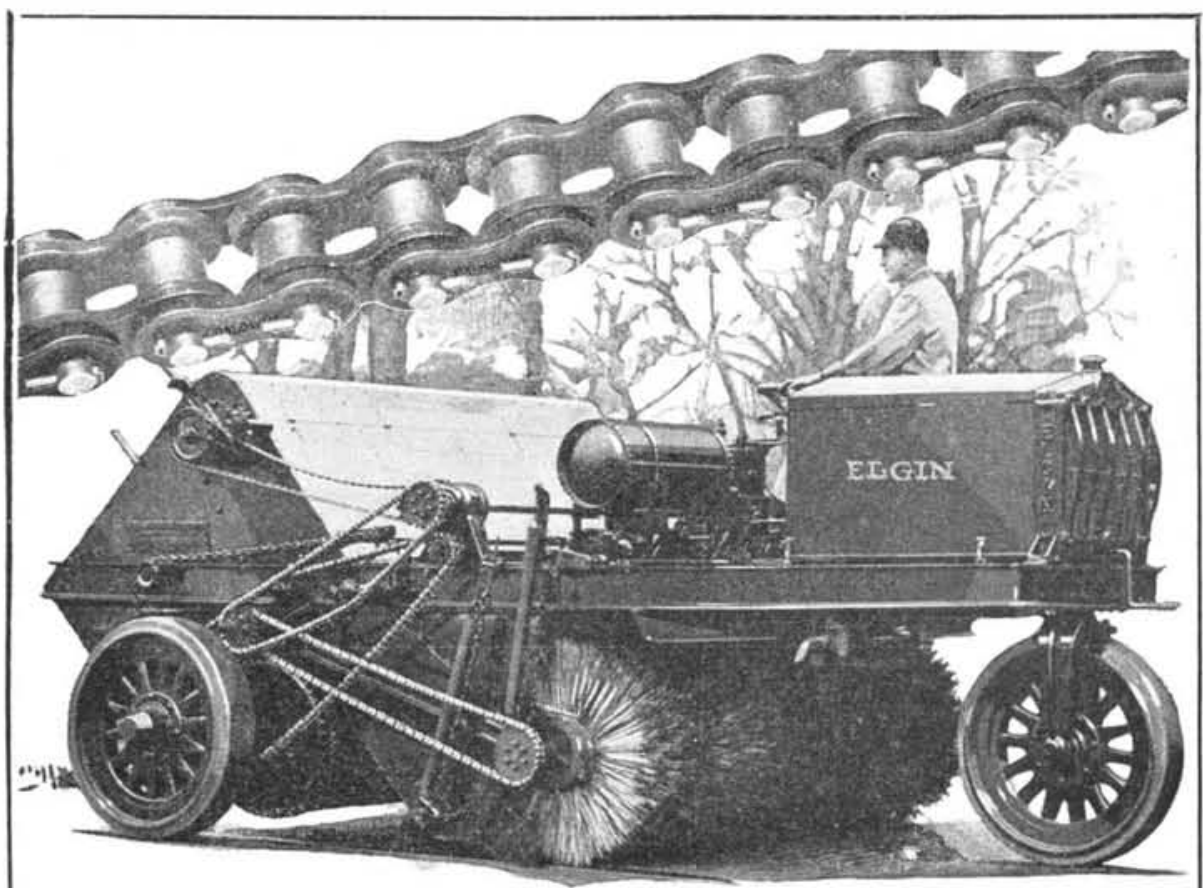

\section{Genuine Baldwin Drive Chains Have Helped} to Revolutionize Street Cleaning Methods

The Elgin Motor Sweeper has rendered obsolete the old wasteful time con suming methods of street cleaning by hand or with horse drawn vehicles.

The successful performance of this machine bespeaks the efficiency and dependability of genuine Baldwin Drive chains and sprockets for these genuine Baldwin products are standard equipment on the Elgin Street Sweeper

The experience and knowledge of Baldwin's engineers are at the disposal

of anynne interested in efficient chain drives for industrial purposes.

\section{BALDWIN CHAIN \& MANUFACTURING COMPANY}

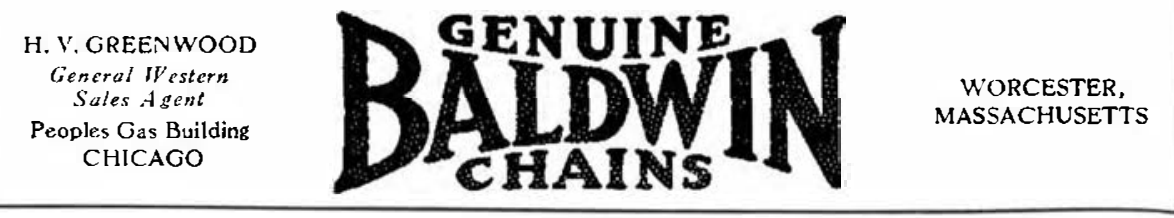

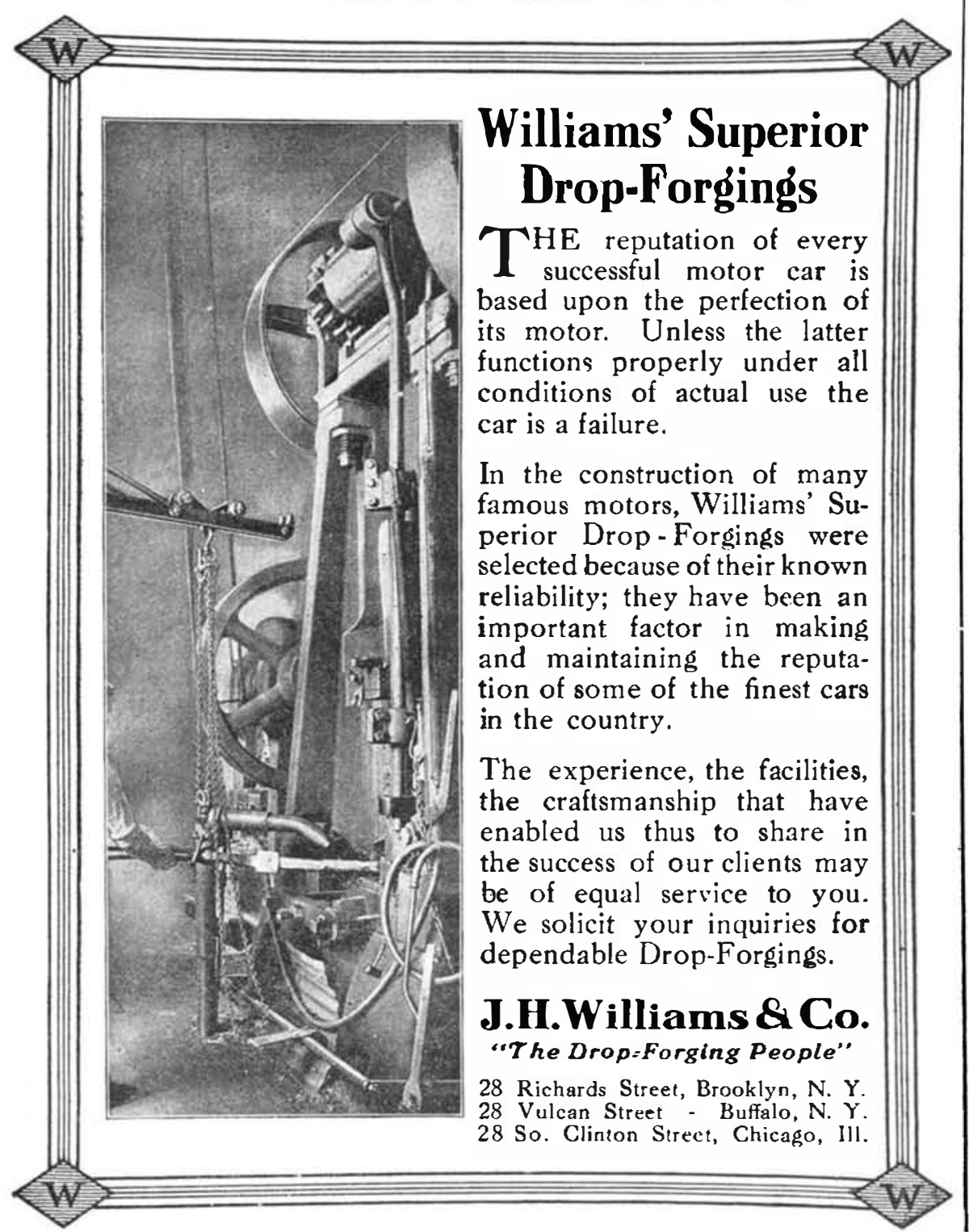

Again the Helicopter?

(Continued from page 577)

peculiar to operation upon an aircrafit Broadly speaking, the mechanism used consists of two geared rings secured to plate steel disks anl placed parallel, one above the other, with interposed geared pinions set oppositcly and horizontallythe pinion's being extensions of the shafts of the propulsive motors. Thus, the operative power is applied equally and in unison to both gear wheels, and continuous contact is assured by rollers bearing upon annular flange-like tracks on the upper and the lower faces of the top and bottom gear wheels, respectively.

Owing to the manner in which the pinions of the prime movers are interposed between the gear wheels, it is entirely practicable to arrange symmetrically a number of engines about this in termediate apparatus and to bring all or only some of them into action as occasion requires. Indeed, it is propose to carry a reserve engine, whch can be thrown in at will or automatically if on of the motors goes dead.

This feature is counted upon to meet a contingency where more speed or lift is desired or to safeguard against disablement when aloft. The one criticism of the present type of helicopter advanced by competent experts is that the machin may not be able to volplane like an airplane if its propulsive power fail. This inability has yet to be established. However, the craft would, undoubtedly, have to return to earth if one of its two motors failed. Even so, with only half of its engine power to draw on, the two propellers should be able to permit the helicopter to settle gradually and at a rate that would not invite damaging impact with the ground.

Post-Bellum Britain and the Inventor (Continued from page 578)

different countries, can be appreciated by an examination of the above chart which shows the total number of patents granted by the Government Patent Offices of the United States of America, Great Britain and Germany, respectively, during the yeans 1901 to 1913 . The chart does not show the number of applications that were filed at the British Patent Office, but only those for which patents were granted alike to subjects of Great Britain and to foreign inventors, the number of patents applied for in England as provisional applications being about double the number that are followed up six months later by the complete applications.

The second chart illustrates the fluctuations in the total number of applications for British patents that were filed and sealed during the years 1903 to 1918, the drop following the outbreak of the war being very great. The falling off that is shown by the chart has been entirely recovered at the present time, as during the first nine months of 1919 , a larger number of applications for British patents has been filed than in any like period before the war.

Considerable doubt has arisen and much debate has followed concerning the levying of annual taxes or fees by way of renewal charges upon inventions that have been patented in most countries of the world other than America. An examination of the third chart will show that in Great Britain only 4.6 per cent (fortysix per thousand) of the patents applied for in that country by residents and foreigners, are considered by their owners as worth keeping alive by the payment of annual fees and taxes up to the end of the fourteenth year. Seeing that under the new British Patents Bill, no annual tax is to become payable until the and of the sixth year and then only five pounds for the seventh year, or but fifty shillings if the patent is made subject to the grant of licenses, the opinion gen- erally held by those who have to work and are actually commercially concerned in developing and carrying the inventions into effect is, that it is an immense advantage to have absolutely removed from the Patent Register those patents that are utterly impracticable and have proved useless and worthless to their owners, as by their continued existence they may not only become opportunities of annoyance and hindrance to other industries, ut when acquired for exploitation purposes by adventurous and irresponsible persons, vexatious and frivolous proceedings may be occasioned in repudiating unjust and unwarranted demands.

\section{Romance of Invention}

(Continued from page 580)

arts, and its manufacture is already a huge industry.

It is possible that the reader has not heard of bakelite. But it is hardly possible that he has not either seen it or used it. Bakelite is made into billiard balls, wireless telegraph apparatus, transparent fountain pens, automobile starters, battleship switchboards, moldings for cameras, phonograph records, casings for precise scientific instruments, telephone receivers, pipe stems, railroad signals, grinding wheels, umbrella handles, articles of ornament, buttons, automobile radiator caps and a few thousand other things.

Without a rather exact chemical knowledge it is difficult to say just what bakelite is, or rather so as to say it that the reader will know what is meanit. To remark that bakelite is oxy-benzyl-methylen-glycol-anhydride is not particularly iluminating.

Bakelite is a synthetic material. It is among the best of the insulating materials and therefore finds an important place in the manufacture of all electrical apparatus. It can be most readily and beautifully machined, and as it may be made of any color and any degree of transparency to complete opaqueness, it finds opportunity to enter into the composition of hundreds of objects formerly made of wood, metal, rubber or celluloid. Bakelite takes a sharp clean-cut impression when molded, which in many manufacturing operations does away with further machining. Because it can be molded it can be incorporated with metal or other material in the process of manufacture. It can be given a smooth and glossy finish in the mold. It does not warp, shrink, or swell.

Any one who imagines a thing like this was produced by a flash of "discovery" should talk to Dr. Baekeland about the amount of labor which went into its production. It was a lengthy process of experiment and disappointment, of investigation and itrial and error, of trying first one means and then another. Into the chemistry of the process it would not be wise here to attempt to go. Suffice it that Dr. Baekeland succeeded in surmounting all the difficulties he met and in producing the substance to which his name has been given.

Dr. Baekeland has much practícal advice to give to the inventor or discoverer of chemical processes of commercial worth, of which perhaps, the most important is "don't spring your discovery just because it is perfect in the laboratory . test it on a commercial scale, even though it is a small scale, before you bring it out for commercial exploitation."

Dr. Baekeland has taken out a great many patents ... just how many he doesn't know himself. Many of these he has had to defend in courts of law ... his friends say he enjoys his law suits almost as much as he does experimenting. and producing the processes which, when patented, and proving to be successful, lead to law suits. In almost all of them he is uniformly successful and "sueing Baekeland" is no longer consid- 